\title{
Anticoagulants, Reperfusion Therapy, and Outcomes in Ischemic Stroke Patients With Non-Valvular Atrial Fibrillation - A Single-Center, 6-Year Experience of 546 Consecutive Patients -
}

\author{
Satoshi Suda, MD, PhD; Yuki Sakamoto, MD; Seiji Okubo, MD, PhD; Junya Aoki, MD, PhD; \\ Takashi Shimoyama, MD, PhD; Takuya Kanamaru, MD, PhD; Kentaro Suzuki, MD; \\ Akihito Kutsuna, MD; Noriko Matsumoto, MD, PhD; Chikako Nito, MD, PhD; \\ Yasuhiro Nishiyama, MD, PhD; Masahiro Mishina, MD, PhD; Kazumi Kimura, MD, PhD
}

\begin{abstract}
Background: This study investigated changes in anticoagulant use, treatment, and functional outcomes in acute ischemic stroke (AIS) patients with non-valvular atrial fibrillation (NVAF) over a 6-year period.

Methods and Results: Patients with AIS and NVAF admitted to our department from April 2011 to March 2017 were analyzed retrospectively. Patients were divided into 3 groups based on the time of the initial visit (Periods 1-3, corresponding to April 2011March 2013, April 2013-March 2015, and April 2015-March 2017, respectively). Associations between prescribed medication prior to event and stroke severity, reperfusion therapy, and outcomes were assessed. There was no significant change in the rate of insufficient warfarin and inappropriately lowered doses of direct oral anticoagulant (DOAC) treatment over time. The number of patients receiving prior DOAC treatment increased, but neurological severity on admission was milder than in the other 2 groups. The rate of reperfusion therapy increased from $19.9 \%$ (Period 1) to $42.7 \%$ (Period 3) for moderate-to-severe stroke patients. Multivariate logistic regression analysis revealed that reperfusion therapy was independently positively associated with good functional outcomes, but negatively associated with mortality (odds ratios [95\% confidence intervals] 7.14 [3.34-15.29] and 0.13 [0.008-0.69], respectively).
\end{abstract}

Conclusions: Inappropriate anticoagulant use for stroke patients with NVAF did not decrease over time. An increase in reperfusion therapy was a strong factor in improved functional outcomes and mortality.

Key Words: Non-valvular atrial fibrillation; Oral anticoagulants; Reperfusion therapy

A trial fibrillation (AF) is the most common cardiac arrhythmia in developed countries. It is known to increase the risk of stroke and death. The number of patients with AF is gradually and steadily increasing in Japan because of the increase in the aging population..$^{1,2}$ It was reported that patients with AF develop severe ischemic stroke and have poorer outcomes after stroke, including mortality, than those without AF.,4

The concept and tools of oral anticoagulant (OAC) therapy for preventing stroke in patients with non-valvular atrial fibrillation (NVAF) and acute therapy for largevessel occlusive stroke have changed in the past 10 years. A meta-analysis of the RE-LY, ROCKET AF, ARISTOTLE, and ENGAGE AF-TIMI 48 trials showed a favorable risk-benefit profile with significant reductions in stroke, intracranial hemorrhage, and mortality. ${ }^{5}$ Direct OAC (DOAC) therapy was approved in Japan in 2011, thereby increasing the anticoagulation therapy options for

\section{Editorial p 2483}

NVAF patients. The Japanese government approved a 4.5-h time window for recombinant tissue-type plasminogen activator (rt-PA) in August 2012. Furthermore, an analysis of 5 pooled trials (MR CLEAN, ESCAPE, REVASCAT, SWIFT PRIME, and EXTEND IA), performed between December 2010 and December 2014, demonstrated that endovascular thrombectomy is beneficial for most patients with acute ischemic stroke (AIS) due to anterior circulation large vessel occlusion. ${ }^{6}$

These major changes may have affected the initial stroke characteristics and outcomes of patients with NVAF; however, temporal trend reports in Japan are scarce. The aim of this study was to investigate the changes in OAC status and reperfusion therapy, as well as changes in the initial clinical characteristics and outcomes of AIS

Received May 14, 2018; revised manuscript received July 19, 2018; accepted July 24, 2018; released online August 30, 2018 Time for primary review: 15 days

Department of Neurological Science, Graduate School of Medicine, Nippon Medical School, Tokyo, Japan

Mailing address: Satoshi Suda, MD, PhD, Department of Neurological Science, Graduate School of Medicine, Nippon Medical School, 1-1-5 Sendagi, Bunkyo-ku, Tokyo 113-8603, Japan. E-mail: suda-sa@nms.ac.jp

ISSN-1346-9843 All rights are reserved to the Japanese Circulation Society. For permissions, please e-mail: cj@j-circ.or.jp 


\begin{tabular}{|c|c|c|c|c|c|}
\hline & $\begin{array}{c}\text { Total } \\
(n=546)\end{array}$ & $\begin{array}{l}\text { Period } 1 \\
(n=136)\end{array}$ & $\begin{array}{c}\text { Period } 2 \\
(n=206)\end{array}$ & $\begin{array}{c}\text { Period } 3 \\
(n=204)\end{array}$ & P-value \\
\hline Female & $230(45.1)$ & $55(40.4)$ & $83(40.3)$ & $92(45.1)$ & 0.5538 \\
\hline Age (years) & 77 [69-85] & $72[65-84]$ & 79 [71-86] & 77 [70-85] & 0.411 \\
\hline $\mathrm{CHADS}_{2}$ score & $2[1-3]$ & $2[1-3]$ & $2[1-3]$ & $2[1-3]$ & 0.0503 \\
\hline $\mathrm{CHA}_{2} \mathrm{DS}_{2}$-VASc score & $4[2-5]$ & $3[2-4]$ & $4[2-5]$ & $4[3-5]$ & 0.014 \\
\hline Preadmission mRS & $0[0-2]$ & $0[0-0]$ & $0[0-2]$ & $0[0-2]$ & 0.012 \\
\hline NIHSS score on admission & 9 [3-20] & 9 [3-19] & $12[5-23]$ & $7[2-18]$ & 0.0745 \\
\hline \multicolumn{6}{|l|}{ Biochemistry at admission } \\
\hline Blood glucose (mg/dL) & $118[102-144]$ & $116[101-147]$ & $121[104-144]$ & 116 [99-138] & 0.6259 \\
\hline eGFR (mL/min/1.73 m²) & $61[48-76]$ & $64[51-80]$ & $63[48-77]$ & 58 [45-71] & 0.0057 \\
\hline \multicolumn{6}{|l|}{ Anticoagulant status prior to the event } \\
\hline No anticoagulant therapy & $391(71.6)$ & $101(74.3)$ & $154(74.8)$ & $136(66.7)$ & 0.1403 \\
\hline Warfarin & $98(18.0)$ & $30(22.1)$ & $37(18.0)$ & $31(15.2)$ & 0.2712 \\
\hline DOAC & $57(10.4)$ & $5(3.7)$ & $15(7.3)$ & $38(18.6)$ & $<0.0001$ \\
\hline Onset to arrival (h) & $4.5[2-14]$ & $7[3.0-14]$ & $4.5[2.0-13.0]$ & $3.3[1.1-16.2]$ & 0.0019 \\
\hline Reperfusion therapy & $172(31.5)$ & $26(19.1)$ & $63(30.6)$ & $83(40.7)$ & 0.0001 \\
\hline rt-PA & $55(10.1)$ & $12(8.8)$ & $23(11.2)$ & $20(9.8)$ & 0.7703 \\
\hline Endovascular therapy & $63(11.5)$ & $7(5.2)$ & $19(9.2)$ & $37(18.1)$ & 0.0005 \\
\hline rt-PA plus endovascular therapy & $54(9.9)$ & $7(5.2)$ & $21(10.2)$ & $26(12.8)$ & 0.0699 \\
\hline Parenchymal hemorrhage & $45(8.2)$ & $8(5.9)$ & $17(8.3)$ & $20(9.8)$ & 0.4362 \\
\hline $\mathrm{mRS}$ at discharge & $3[1-5]$ & $3[1-5]$ & $3[1-5]$ & $3[1-4]$ & 0.8795 \\
\hline NIHSS score on discharge & $3[0-13]$ & $4[1-18]$ & $3[0-14]$ & $2[0-9]$ & 0.0276 \\
\hline Mortality during hospitalization & $41(7.5)$ & $15(11.0)$ & $19(9.2)$ & $7(3.4)$ & 0.0167 \\
\hline
\end{tabular}

The study was divided into 3 periods, based on the time of the initial visit: Period 1, April 2011-March 2013; Period 2, April 2013-March 2015; Period 3, April 2015-March 2017. Data are given as the median [interquartile range] or as $\mathrm{n}$ (\%). DOAC, direct oral anticoagulant; eGFR, estimated glomerular filtration rate; mRS, modified Rankin Scale; NIHSS, National Institutes of Health Stroke Scale; rt-PA, recombinant tissue-type plasminogen activator.

patients with NVAF over a 6-year period.

\section{Methods}

\section{Subjects}

From April 2011 (when dabigatran, the first DOAC available in Japan, was introduced to the market) through March 2017, consecutive AIS or transient ischemic attack (TIA) patients with NVAF who were admitted to our institute within 7 days from symptom onset were retrospectively recruited from a prospective registry. Patients with a history of rheumatic heart disease and prosthetic mechanical heart valves were excluded. This study was approved by the ethics committee of Nippon Medical School and conformed to the tenets of the Declaration of Helsinki. All participants or participant family members provided written informed consent prior to study participation.

\section{Clinical Characteristics}

$\mathrm{AF}$ at the initial visit was diagnosed using a 12-lead surface electrocardiogram and 24-h Holter recordings. AF was also diagnosed on the basis of any medical history of AF recorded by referring physicians. Clinical background characteristics, including sex, age, prestroke $\mathrm{CHADS}_{2}$ score or $\mathrm{CHA}_{2} \mathrm{DS}_{2}-\mathrm{VASc}$ score, blood glucose concentrations, estimated glomerular filtration rate (eGFR), and $\mathrm{OAC}$ status, were recorded on admission. However, aortic plaques were not assessed as a component of the score because transesophageal echocardiography was performed for approximately only one-quarter of patients included in the present study. Insufficient treatment with warfarin (corresponding to warfarin treatment and a prothrombin time-international normalized ratio [PT-INR] on admission of $<2.0$ for patients $<70$ years of age and a PT-INR $<1.6$ for patients aged $\geq 70$ years) was determined based on previous studies in Japan and on domestic guidelines. ${ }^{7-9}$ Inappropriately lowered doses of DOAC were defined as the administration of low-dose DOAC despite the standard dosage criteria being met based on the domestic label (Table S1). Magnetic resonance imaging (MRI) studies, including diffusion-weighted imaging and time-of-flight magnetic resonance angiography (MRA), were performed on admission using a commercially available echo planar instrument operating at $1.5 \mathrm{~T}$ (Echelon Oval; Hitachi Medical Systems, Tokyo, Japan). Patients with MRI contraindications were evaluated with computed tomography (CT) angiography or conventional angiography. CT was performed at least once within $48 \mathrm{~h}$ after admission, and parenchymal hemorrhagic transformation was defined as a hematoma that was $\leq 30 \%$ of the infarcted area with some slight space-occupying effects (PH-1) or as a dense a hematoma when it was $>30 \%$ of the infarcted area with substantial space-occupying effect or as any hemorrhagic lesion outside the infarcted area (PH-2). ${ }^{10}$ Stroke severity was assessed using the National Institutes of Health Stroke Scale (NIHSS) score on admission. Initial stroke severity was defined as mild (NIHSS score 0-9), moderate (NIHSS score 10-19), or severe (NIHSS score $\geq 20$ ). Functional outcomes were assessed using the modified Rankin scale (mRS) score and NIHSS score at the time of discharge. A good discharge outcome was defined as an mRS score of 
(A)

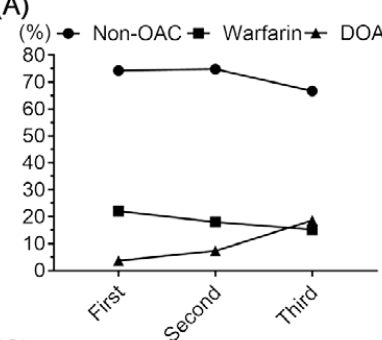

(C)

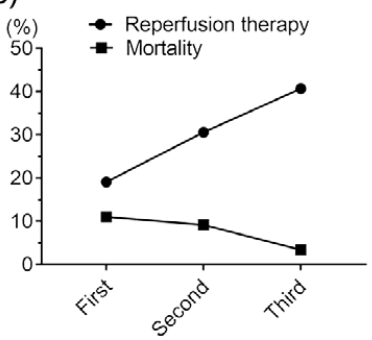

(B)

(\%) - Insufficient warfarin

$\left.{ }^{80}\right]$ - Inappropriately lowered dose DOAC

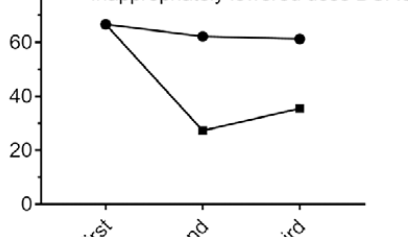

(D)

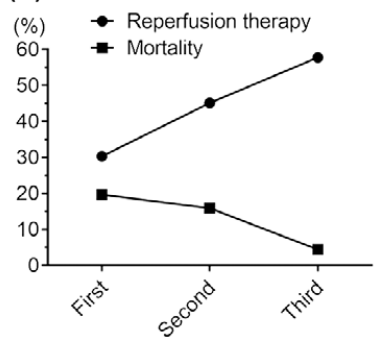

(E)

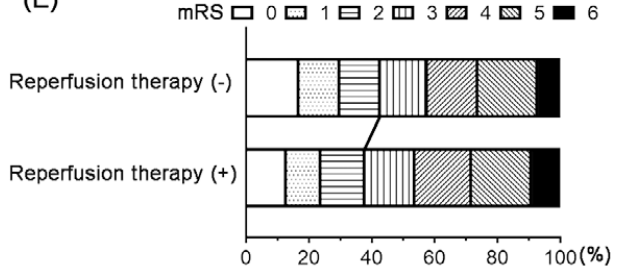

(F)

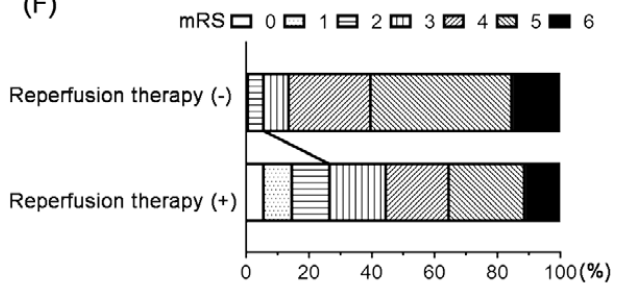

Figure. (A-D) Changes in oral anticoagulants status $(\mathbf{A})$ and insufficient warfarin therapy and inappropriately lowered doses of direct oral anticoagulants (DOAC) over time (B), as well as in the relationship between reperfusion therapy and mortality over time in all patients (C) and in patients with moderate-to-severe stroke severity (D), defined as those with an initial National Institutes of Health Stroke Scale (NIHSS) score $\geq 10$. The study was divided into 3 periods: first. April 2011-March 2013; second, April 2013-March 2015; third, April 2015-March 2017. (E,F) Differences in modified Rankin scale (mRS) scores with and without reperfusion therapy at discharge in all patients $(\mathbf{E})$ and in patients with moderate-to-severe stroke severity $(\mathbf{F})$, defined as an initial NIHSS score $\geq 10$

\begin{tabular}{|c|c|c|c|c|}
\hline & \multicolumn{2}{|c|}{ Mild stroke } & \multicolumn{2}{|c|}{ Mild-moderate stroke } \\
\hline & OR $(95 \% \mathrm{Cl})$ & P-value & OR $(95 \% \mathrm{Cl})$ & P-value \\
\hline Age (per 10 years) & $0.67(0.51-0.87)$ & 0.0024 & $0.75(0.56-1.01)$ & 0.0560 \\
\hline Female & $0.88(0.57-1.36)$ & 0.5646 & $0.73(0.45-1.18)$ & 0.1977 \\
\hline Pre-mRS score (per 1 point) & $0.74(0.63-0.86)$ & $<0.0001$ & $0.78(0.67-0.91)$ & 0.0012 \\
\hline $\mathrm{CHA}_{2} \mathrm{DS}_{2}$-VASc score (per 1 point) & $1.04(0.96-1.21)$ & 0.6520 & $0.99(0.84-1.17)$ & 0.8950 \\
\hline Blood glucose level (per $10 \mathrm{mg} / \mathrm{dL}$ ) & $0.91(0.86-0.96)$ & 0.0003 & $0.95(0.90-1.00)$ & 0.0741 \\
\hline eGFR $<60 \mathrm{~mL} / \mathrm{min} / 1.73 \mathrm{~m}^{2}$ & $0.88(0.59-1.32)$ & 0.5445 & $0.84(0.75-1.88)$ & 0.4590 \\
\hline Prescribed DOAC & $2.48(1.21-5.08)$ & 0.0130 & $3.35(1.24-9.03)$ & 0.0168 \\
\hline
\end{tabular}

$\mathrm{Cl}$, confidence interval; OR, odds ratio. Other abbreviations as in Table 1.

$0-2$, and a poor outcome was defined as an $\mathrm{mRS}$ score of $3-5$ or death (mRS score of 6$)$.

\section{Statistical Analysis}

Patients were divided into 3 groups based on the year of the initial visit: Period 1, April 2011-March 2013 ( $\mathrm{n}=136$ ); Period 2, April 2013-March $2015(\mathrm{n}=206)$; and Period 3, April 2015-March $2017(\mathrm{n}=204)$. We initially compared demographics and clinical characteristics between the 3 time periods. Then, patients were divided into 3 groups based on the prescribed medication prior to the index event: no OAC, warfarin treatment, and DOAC treatment. The association between the admission NIHSS score and anticoagulant status prior to stroke was assessed using multivariate logistic models. Furthermore, we compared clinical characteristics of all patients and patients who experienced moderate-to-severe stroke (initial NIHSS score $\geq 10$ ) in accordance with discharge outcomes and mortality during hospitalization. ${ }^{11}$ Age, sex, and variables with $\mathrm{P}<0.05$ in the univariate analysis were entered into a multivariate logistic regression model to identify variables independently associated with poor functional outcome and mortality. Data are presented as the median (interquartile range $[\mathrm{IQR}]$ ) or as number (\%). Odds ratios (ORs) are presented with corresponding $95 \%$ confidence intervals (CIs). All analyses were performed using JMP version 13 (SAS Institute, Cary, NC, USA) and $\mathrm{P}<0.05$ was considered significant.

\section{Results}

In all, 546 consecutive patients with NVAF and AIS or TIA (230 females; median age 77 years [IQR 69-85 years]; median NIHSS score 9 [IQR, 3-20]) were enrolled in the 


\begin{tabular}{|c|c|c|c|c|c|}
\hline & $\begin{array}{c}\text { Total } \\
(\mathrm{n}=269)\end{array}$ & $\begin{array}{l}\text { Period } 1 \\
(n=66)\end{array}$ & $\begin{array}{c}\text { Period } 2 \\
(n=113)\end{array}$ & $\begin{array}{c}\text { Period } 3 \\
(n=90)\end{array}$ & P-value \\
\hline Female & $129(48.0)$ & $32(48.4)$ & $55(48.7)$ & $42(46.7)$ & 0.9557 \\
\hline Age (years) & 80 [72-87] & 82 [73-89] & 80 [74-87] & 79 [72-86] & 0.2551 \\
\hline $\mathrm{CHADS}_{2}$ score & $2[1-3]$ & $2[1-3]$ & $2[1-3]$ & $2[1-3]$ & 0.9360 \\
\hline $\mathrm{CHA}_{2} \mathrm{DS}_{2}-\mathrm{VASc}$ score & $4[3-5]$ & $4[3-5]$ & $4[3-5]$ & $4[3-5]$ & 0.8728 \\
\hline Preadmission mRS & $0[0-2]$ & $0[0-3]$ & $0[0-3]$ & $0[0-3]$ & 0.4403 \\
\hline NIHSS score on admission & 20 [15-26] & 20 [14-26] & 21 [17-28] & 19 [13-24] & 0.0574 \\
\hline \multicolumn{6}{|l|}{ Biochemistry at admission } \\
\hline Blood glucose (mg/dL) & $125[102-144]$ & $123[101-152]$ & $124[108-148]$ & 126 [109-162] & 0.3255 \\
\hline eGFR $\left(\mathrm{mL} / \mathrm{min} / 1.73 \mathrm{~m}^{2}\right)$ & $58[45-74]$ & $62[49-76]$ & 57 [41-73] & $56[46-71]$ & 0.578 \\
\hline Onset to arrival (h) & $3.0[1.7-9.7]$ & $3.8[2.5-12]$ & $3.5[2.0-10.0]$ & $1.7[0.9-6.0]$ & 0.0001 \\
\hline Reperfusion therapy & $123(31.5)$ & $20(30.3)$ & $51(45.1)$ & $52(57.8)$ & 0.0030 \\
\hline rt-PA & $34(12.6)$ & $8(12.1)$ & $19(16.8)$ & $7(7.8)$ & 0.1552 \\
\hline Endovascular therapy & $47(17.4)$ & $7(10.6)$ & 15 (13.3) & $25(27.8)$ & 0.0062 \\
\hline rt-PA plus endovascular therapy & $42(15.6)$ & $5(7.6)$ & $17(15.0)$ & $20(22.2)$ & 0.0440 \\
\hline Parenchymal hemorrhage & $45(8.2)$ & $5(7.6)$ & $8(7.1)$ & $14(15.6)$ & 0.1016 \\
\hline $\mathrm{mRS}$ at discharge (IQR) & $5[4-5]$ & $5[4-5]$ & $5[4-5]$ & $4[3-5]$ & 0.1043 \\
\hline NIHSS score on discharge & $12[4-22]$ & $16[8-30]$ & 12 [4-23] & 9 [3-16] & 0.0002 \\
\hline Mortality during hospitalization & $35(13.0)$ & $13(19.7)$ & $18(15.9)$ & $4(4.4)$ & 0.0096 \\
\hline
\end{tabular}

The study was divided into 3 periods, based on the time of the initial visit: Period 1, April 2011-March 2013; Period 2, April 2013-March 2015; Period 3, April 2015-March 2017. Data are given as the median [IQR] or as n (\%). IQR, interquartile range. Other abbreviations as in Table 1.

\begin{tabular}{|c|c|c|c|c|c|c|}
\hline & \multirow{2}{*}{$\begin{array}{c}\text { Total } \\
(n=269)\end{array}$} & \multirow{2}{*}{$\begin{array}{l}\text { Good outcome } \\
\qquad(n=44)\end{array}$} & \multirow{2}{*}{$\begin{array}{l}\text { Poor outcome } \\
\quad(n=225)\end{array}$} & \multirow{2}{*}{ P-value } & \multicolumn{2}{|c|}{ Multivariate analysis } \\
\hline & & & & & OR $(95 \% \mathrm{Cl})$ & P-value \\
\hline Female & $129(48.0)$ & $13(29.6)$ & $116(51.6)$ & 0.0075 & $0.79(0.33-1.90)$ & 0.6040 \\
\hline Age (years) & 80 [72-87] & 77 [66-85] & $81[74-87]$ & 0.0069 & $0.99(0.94-1.04)$ & 0.6372 \\
\hline $\mathrm{CHADS}_{2}$ score & $2[1-3]$ & $2[1-2]$ & $2[1-3]$ & 0.0026 & & \\
\hline $\mathrm{CHA}_{2} \mathrm{DS}_{2}$-VASc score & $4[3-5]$ & $3[2-5]$ & $4[3-5]$ & 0.0005 & $0.79(0.58-1.05)$ & 0.1041 \\
\hline Preadmission mRS & $0[0-2]$ & $0[0-0]$ & $0[0-3]$ & 0.0105 & $0.89(0.65-1.18)$ & 0.4284 \\
\hline NIHSS score on admission & 20 [15-26] & 18 [11-23] & $21[16-26]$ & 0.0025 & $0.92(0.86-0.97)$ & 0.0042 \\
\hline \multicolumn{7}{|l|}{ Biochemistry at admission } \\
\hline Blood glucose (mg/dL) & $125[102-144]$ & 133 [103-159] & $124[106-153]$ & 0.7553 & & \\
\hline eGFR $\left(\mathrm{mL} / \mathrm{min} / 1.73 \mathrm{~m}^{2}\right)$ & $58[45-74]$ & $62[51-77]$ & $57[43-74]$ & 0.1407 & & \\
\hline Onset to arrival (h) & $3.0[1.7-9.7]$ & $2.0[0.8-3.4]$ & $3.7[2.0-10.0]$ & 0.0005 & $1.01(0.97-1.02)$ & 0.6578 \\
\hline Reperfusion therapy & $123(31.5)$ & $34(77.3)$ & $89(39.6)$ & $<0.0001$ & $5.55(2.39-12.87)$ & $<0.0001$ \\
\hline rt-PA & $34(12.6)$ & $10(22.7)$ & $24(10.7)$ & 0.0277 & & \\
\hline Endovascular therapy & $47(17.4)$ & $8(18.2)$ & $39(17.3)$ & 0.8922 & & \\
\hline rt-PA plus endovascular therapy & $42(15.6)$ & $16(36.4)$ & $26(11.6)$ & $<0.0001$ & & \\
\hline Parenchymal hemorrhage & $27(10.0)$ & $3(6.8)$ & $24(10.7)$ & 0.4372 & & \\
\hline
\end{tabular}

Unless indicated otherwise, data are given as the median [IQR] or as $\mathrm{n}(\%)$. Abbreviations as in Tables $1-3$.

present study. There were $136(24.9 \%), 206(37.7 \%)$, and $204(37.4 \%)$ patients in the Period 1, 2, and 3 groups, respectively.

The clinical background characteristics of the patients in this study overall and for each period over the 6 years of the study are given in Table 1 and Figure. There were significant differences in $\mathrm{CHA}_{2} \mathrm{DS}_{2}-\mathrm{VASc}$ scores $(\mathrm{P}=0.0014)$, preadmission $\mathrm{mRS}$ scores $(\mathrm{P}=0.012)$, and eGFR $(\mathrm{P}=0.0057)$ among the 3 groups. The proportion of reperfusion therapy increased steadily from $19.1 \%(n=26)$ during Period 1 to $40.7 \%(n=83)$ during Period $3(\mathrm{P}<0.0001)$. The occurrence of hemorrhagic transformation increased slightly from $5.9 \%(n=8)$ during Period 1 to $9.8 \%(n=20)$ Period 3, but the difference was not statistically significant $(\mathrm{P}=0.4362)$. Figure A shows the change in OAC status over time. The proportion of patients not receiving OAC in Periods 1, 2, and 3 was $74.3 \%, 74.8 \%$, and $66.7 \%$, respectively $(\mathrm{P}=0.1403)$. The proportion of prior DOAC use increased significantly from $3.7 \%(n=5)$ in Period 1 to $18.1 \%(n=37)$ in Period 3 $(\mathrm{P}<0.0001)$, whereas warfarin use decreased slightly from $22.1 \%(n=30)$ in Period 1 to $15.2 \%(n=31)$ in Period 3 $(\mathrm{P}=0.2712)$. Furthermore, there were no significant changes 


Table 5. Clinical, Laboratory, and Procedural Factors for Mortality Among Moderate-to-Severe Stroke Patients (Admission National
Institutes of Health Stroke Scale Score $\geq \mathbf{1 0})$
in Univariate and Multivariate Analyses

Unless indicated otherwise, data are given as the median [IQR] or as $\mathrm{n}(\%)$. Abbreviations as in Tables 1-3.

\begin{tabular}{|c|c|c|c|c|c|c|}
\hline & \multirow{2}{*}{$\begin{array}{c}\text { Total } \\
(n=546)\end{array}$} & \multirow{2}{*}{$\begin{array}{l}\text { Good outcome } \\
(n=227)\end{array}$} & \multirow{2}{*}{$\begin{array}{l}\text { Poor outcome } \\
\quad(n=319)\end{array}$} & \multirow{2}{*}{ P-value } & \multicolumn{2}{|c|}{ Multivariate analysis } \\
\hline & & & & & OR $(95 \% \mathrm{Cl})$ & P-value \\
\hline Female sex & $230(45.1)$ & $71(31.3)$ & $159(49.8)$ & $<0.0001$ & $0.97(0.57-1.67)$ & 0.9220 \\
\hline Age (years) & 77 [69-85] & 74 [67-81] & 81 [74-87] & $<0.0001$ & $0.95(0.92-0.98)$ & 0.0031 \\
\hline $\mathrm{CHADS}_{2}$ score & $2[1-3]$ & $2[1-3]$ & $2[1-3]$ & $<0.0001$ & & \\
\hline $\mathrm{CHA}_{2} \mathrm{DS}_{2}$-VASc score & $4[2-5]$ & $3[2-4]$ & $4[3-5]$ & $<0.0001$ & $0.94(0.78-1.14)$ & 0.5561 \\
\hline Preadmission mRS & 0 [0-2] & $0[0-0]$ & $0[0-3]$ & $<0.0001$ & $0.57(0.44-0.59)$ & $<0.0001$ \\
\hline NIHSS score on admission & $3[0-13]$ & $3[1-7]$ & $17[7-24]$ & $<0.0001$ & $0.87(0.84-0.90)$ & $<0.0001$ \\
\hline \multicolumn{7}{|l|}{ Biochemistry at admission } \\
\hline Blood glucose (mg/dL) & 118 [102-144] & 113 [98-138] & $121[104-151]$ & 0.0087 & $1.00(0.99-1.00)$ & 0.3707 \\
\hline eGFR $\left(\mathrm{mL} / \mathrm{min} / 1.73 \mathrm{~m}^{2}\right)$ & $61[48-76]$ & $65[54-77]$ & 59 [43-75] & 0.0014 & $0.99(0.98-1.00)$ & 0.2249 \\
\hline Onset to arrival (h) & $4.5[2-14]$ & $4.0[2.0-17.1]$ & $4.5[2.0-13.3]$ & 0.9286 & & \\
\hline Reperfusion therapy & $172(31.5)$ & $65(28.6)$ & $107(33.5)$ & 0.2237 & & \\
\hline rt-PA & $55(10.1)$ & 27 (11.9) & $28(8.8)$ & 0.2330 & & \\
\hline Endovascular therapy & $63(11.5)$ & $16(7.1)$ & $47(14.7)$ & 0.0056 & $1.71(0.70-4.18)$ & 0.2356 \\
\hline rt-PA plus endovascular therapy & $54(9.9)$ & $22(9.7)$ & $32(10.0)$ & 0.8957 & & \\
\hline Parenchymal hemorrhage & $45(8.2)$ & $12(5.3)$ & $33(10.3)$ & 0.0341 & $0.37(0.15-0.94)$ & 0.0358 \\
\hline
\end{tabular}

Unless indicated otherwise, data are given as the median [IQR] or as $n(\%)$. Abbreviations as in Tables 1-3.

in the rate of insufficient warfarin therapy $(\mathrm{P}=0.8955)$ and inappropriately lowered DOAC doses over time $(\mathrm{P}=0.4501$; Figure $\mathrm{B})$. The mortality rate decreased significantly from $11.0 \%(n=15)$ in Period 1 to $3.4 \%(n=7)$ in Period 1 ( $\mathrm{P}=0.0167$; Figure $\mathbf{C})$.

Clinical background characteristics of the patients according to prior OAC status are given in Table S2. Admission NIHSS scores were significantly lower in the DOAC than no OAC $(\mathrm{P}=0.0370)$ and warfarin $(\mathrm{P}=0.0085)$ groups, but there was no significant difference in NIHSS scores at admission between the no OAC and WF groups $(\mathrm{P}=0.2591)$. The percentage of patients with hemorrhagic transformation during the acute phase did not differ among the 3 groups $(\mathrm{P}=0.9882)$. Discharge $\mathrm{mRS}$ and NIHSS scores did not differ significantly among the 3 groups $(\mathrm{P}=0.5111$ and $\mathrm{P}=0.7004$, respectively $)$. The clinical background characteristics of the patients according to stroke severity on admission are given in Table S3. There were significant differences in age $(\mathrm{P}<0.0001)$, sex $(\mathrm{P}=0.0065), \mathrm{CHADS}_{2}$ score $(\mathrm{P}=0.0071), \mathrm{CHA}_{2} \mathrm{DS}_{2}-\mathrm{VASc}$ score $(\mathrm{P}=0.0003)$, preadmission $\mathrm{mRS}$ score $(\mathrm{P}<0.0001)$, blood glucose levels $(\mathrm{P}=0.0002)$, eGFR $(\mathrm{P}=0.0077)$, and prior DOAC use $(\mathrm{P}=0.0458)$ between those who experienced mild and moderate-to-severe strokes. Multivariate logistic analysis showed that prior DOAC treatment was independently associated with mild stroke (NIHSS score $<10$; OR 2.48; 95\% CI 1.21-5.08; $\mathrm{P}=0.0130$ ) and mildmoderate stroke on admission (NIHSS score <20; OR 3.35; 95\% CI 1.24-9.03; $\mathrm{P}=0.0168$; Table 2).

Table 3 lists the clinical background characteristics of 


\begin{tabular}{|c|c|c|c|c|c|c|}
\hline & \multirow{2}{*}{$\begin{array}{c}\text { Total } \\
(n=546)\end{array}$} & \multirow{2}{*}{$\begin{array}{c}\text { No mortality } \\
(n=505)\end{array}$} & \multirow{2}{*}{$\begin{array}{c}\text { Mortality } \\
(n=41)\end{array}$} & \multirow{2}{*}{ P-value } & \multicolumn{2}{|c|}{ Multivariate analysis } \\
\hline & & & & & OR (95\% Cl) & P-value \\
\hline Female & $230(45.1)$ & $209(41.4)$ & $21(51.2)$ & 0.2201 & $1.53(0.66-3.56)$ & 0.31175 \\
\hline Age (years) & 77 [69-85] & $80[72-87]$ & 84 [75-88] & 0.0008 & $1.98(1.24-3.23)$ & 0.0042 \\
\hline $\mathrm{CHADS}_{2}$ score & $2[1-3]$ & $2[1-3]$ & $3[2-3]$ & 0.2296 & & \\
\hline $\mathrm{CHA}_{2} \mathrm{DS}_{2}$-VASc score & $4[2-5]$ & $4[2-5]$ & $4[3-5]$ & 0.1757 & & \\
\hline Preadmission mRS & $0[0-2]$ & $0[0-1]$ & $0[0-3]$ & 0.0716 & $1.12(0.89-1.41)$ & 0.3191 \\
\hline NIHSS score on admission & $3[0-13]$ & 8 [2-19] & 22 [13-29] & $<0.0001$ & $1.08(1.04-1.12)$ & $<0.0001$ \\
\hline \multicolumn{7}{|l|}{ Biochemistry at admission } \\
\hline Blood glucose (mg/dL) & $118[102-144]$ & $118[101-144]$ & $125[113-160]$ & 0.0745 & $1.01(0.99-1.01)$ & 0.1563 \\
\hline eGFR (mL/min/1.73 m²) & $61[48-76]$ & $62[48-76]$ & 56 [40-75] & 0.1876 & & \\
\hline Onset to arrival (h) & $4.5[2-14]$ & $4.5[2.0-15.0]$ & $4.0[2.5-10.5]$ & 0.6108 & & \\
\hline Reperfusion therapy & $172(31.5)$ & $157(31.1)$ & $15(36.6)$ & 0.4662 & & \\
\hline rt-PA & $55(10.1)$ & $50(9.0)$ & $5(12.2)$ & 0.6388 & & \\
\hline Endovascular therapy & $63(11.5)$ & $56(11.1)$ & $7(17.1)$ & 0.2487 & & \\
\hline rt-PA plus endovascular therapy & $54(9.9)$ & $51(10.1)$ & $3(7.3)$ & 0.5661 & & \\
\hline Parenchymal hemorrhage & $45(8.2)$ & $43(8.5)$ & $2(4.9)$ & 0.4154 & & \\
\hline
\end{tabular}

Unless indicated otherwise, data are given as the median [IQR] or as $\mathrm{n}(\%)$. Abbreviations as in Tables 1-3.

patients with moderate to severe stroke (initial NIHSS score $\geq 10$ ) over the 6 -year study period. There were no differences in admission NIHSS scores among the 3 groups (i.e., Periods $1-3 ; \mathrm{P}=0.0574)$. The time from onset to hospital arrival was shortened $(\mathrm{P}=0.0001)$ and reperfusion therapy, especially endovascular treatment (EVT) alone $(\mathrm{P}=0.0062)$ and rt-PA plus EVT $(\mathrm{P}=0.0440)$, increased significantly. There was a significant difference in discharge NIHSS scores among the 3 groups (median values 16, 12, and 9 during Periods 1, 2, and 3, respectively; $\mathrm{P}=0.0002$ ). Moreover, the mortality rate decreased significantly from $19.7 \%$ during Period 1 to $4.4 \%$ during Period 3 ( $\mathrm{P}=0.0096$; Figure D).

Tables 4,5 show the associations between baseline characteristics related to functional outcome at discharge and mortality during hospitalization for patients with moderate to severe stroke. Multivariate logistic regression analysis revealed that reperfusion therapy (OR 5.55; 95\% CI 2.39-12.87) was independently and positively associated with good functional outcomes, whereas initial NIHSS score (OR 0.92 ; 95\% CI 0.86-0.97) was negatively associated with good functional outcomes (Table 4). Moreover, rt-PA plus EVT (OR 0.13; 95\% CI 0.0008-0.69) was independently and negatively associated with mortality, and NIHSS score on admission was positively associated with mortality (OR 1.08; 95\% CI 1.03-1.14; Table 5). The distribution of mRS scores (0-6) across all patients in whom reperfusion was used was as follows: $0,17.4 \% ; 1,13.4 \% ; 2$, $12.3 \% ; 3,14.2 \% ; 4,16.3 \% ; 5,19.3 \%$; and $6,7.1 \%$. The distribution of $\mathrm{mRS}$ scores across all patients in whom reperfusion was not used was as follows: $0,17.4 \% ; 1,13.1 \% ; 2$, $12.8 \% ; 3,14.7 \% ; 4,16.0 \% ; 5,19.0 \%$; and $6,7.0 \%$. In patients with moderate to severe stroke (initial NIHSS score $\geq 10$ ), the distribution of $\mathrm{mRS}$ scores across all patients in whom reperfusion was used was as follows: 0 , $12.8 \% ; 1,11.0 \% ; 2,14.0 \% ; 3,15.7 \% ; 4,18.6 \% ; 5,19.2 \%$; and $6,8.7 \%$ (Figure E). Across all patients with moderate to severe stroke (initial NIHSS score $\geq 10$ ) in whom reperfusion was not used, the distribution of mRS scores was as follows: $0,0 \% ; 1,1.4 \% ; 2,5.5 \% ; 3,7.5 \% ; 4,26.0 \% ; 5$,
$44.5 \%$; and $6,15.1 \%$. The distribution of mRS scores in patients with moderate to severe stroke severity in whom reperfusion was used was as follows: $0,6.5 \% ; 1,8.9 \% ; 2$, $12.2 \% ; 3,17.9 \% ; 4,20.3 \% ; 5,23.6 \%$; and 6, 10.6\% (Figure F). There was no independent association between reperfusion therapy and discharge outcome and mortality during hospitalization for all patients (Tables 6,7).

\section{Discussion}

The main finding of the present study is that there was no marked change in the prescription rate for those with prior use of non-OAC therapy, insufficient warfarin therapy, and inappropriately lowered doses of DOAC during the 6 -year study period. The number of patients using DOAC therapy prior to stroke increased gradually, but this may have been associated with milder stroke severity for AIS patients with NVAF. In addition, reperfusion therapy increased steadily, and this increase could be a strong factor in the improved functional outcomes and decreased mortality rates for AIS patients with NVAF.

We found that approximately $60 \%$ of warfarin users with stroke were under-dosed over time. Several large AF registries in Japan have reported that approximately $30-40 \%$ of warfarin users are under-dosed. ${ }^{12,13}$ The present study investigated stroke patients, so the rate of underdosed warfarin users should be relatively high. In addition, the mean age of prior warfarin users in this study was 79 years, which is older than that of patients in the J-RHYTHM Registry (69 years), SAKURA AF Registry (72 years), and FUSHIMI AF Registry (74 years). ${ }^{12-14}$ This may have been related to the physician's intention to avoid bleeding complications, especially intracranial hemorrhage. Conversely, the proportion of inappropriately lowered doses of DOAC was $27.3 \%$ and $35.5 \%$ during Periods 2 and 3 in this study, which is consistent with previous research. ${ }^{12}$ The proportion of inappropriately lowered doses of DOAC during Period 1 was $66.7 \%$, which is high compared with the proportion in Periods 2 and 3, although the difference did not reach statistical significance. Since 
DOAC was first approved in March 2011, only a few DOAC users were enrolled $(n=5)$.

Compared with no anticoagulation, sufficient warfarin therapy was reported to be associated with mild severity and good clinical outcomes for ischemic stroke in AF patients. ${ }^{15,16}$ However, the relationships between prior DOAC treatment and initial stroke severity, as well as functional outcomes, have not been fully investigated.17,18 The present study showed that DOAC medication prior to the event was independently associated with mild or nonsevere stroke on admission. However, discharge NIHSS and mRS scores did not differ among those with prior OAC use. In the present study, the median PT-INR was 1.47 and 62 of 98 patients $(63 \%)$ were in the PT-INR subtherapeutic range, similar to previous reports. ${ }^{19,20}$ These results indicate that it is difficult to control the therapeutic range of warfarin for older patients with $\mathrm{AF}$ who are at high risk of stroke.

There was no significant difference in the initial stroke index during the 6-year period. Conversely, the $\mathrm{CHA}_{2} \mathrm{DS}_{2}-$ VASc and preadmission mRS scores increased as time progressed. The proportion of patients with a history of stroke increased gradually from $21.3 \%$ in Period 1 to $28.9 \%$ in Period 3. In addition, there was an increase in the proportion of patients aged $>75$ years from $58.1 \%$ in Period 1 to $65.7 \%$ in Period 3. These 2 changes may have affected the $\mathrm{CHA}_{2} \mathrm{DS}_{2}$-VASc score and preadmission mRS. We found significant changes in the time from onset and the rate of reperfusion therapy, especially for EVT alone and rt-PA plus EVT; subsequently, functional outcomes, including mortality, improved markedly. Endovascular thrombectomy is beneficial for most patients with AIS caused by occlusion of the proximal anterior circulation, regardless of patient characteristics or geographic location. ${ }^{6}$ Recently, a retrospective case series showed a strong correlation between reperfusion and the outcomes of patients with vertebrobasilar occlusion strokes treated with EVT, with a 10-fold increase in the likelihood of attaining good functional outcomes if successful reperfusion is attained and twice as high mortality rates for non-recanalized patients. However, the present study was a single-center retrospective observational study. Therefore, interpretation of the present findings requires considerable caution.

The present study had several limitations. First, the mRS score at the time of hospital discharge did not necessarily reflect long-term prognosis. This may have led to the under- or overestimation of the effects of reperfusion therapy on discharge outcome. Second, anticoagulant status prior to stroke was defined based on prescription information, and information regarding drug adherence was not systematically collected. This may have led to underestimation of the effect of DOAC treatment on the initial stroke severity and hemorrhagic transformation after reperfusion therapy. Recently, the continuous prescription rate was reported to be significantly lower for DOAC than warfarin for Japanese patients with NVAF.21 The findings of the present study should be confirmed using a larger prospective cohort. Third, our institution is an EVT-capable comprehensive stroke center with a relatively high rate of reperfusion therapy, especially EVT. ${ }^{22}$ Patients were highly selected and bias may be present. Therefore, the results of the present study may not be generalizable.

\section{Conclusions}

Based on our experiences over a 6-year period, more appropriate OAC treatment and a greater increase in reperfusion therapy for AIS patients with AF are required to prevent stroke and improve outcomes.

\section{Acknowledgment}

The authors thank Miyuki Nakagawa for assistance with database registration.

\section{Sources of Funding / Disclosures}

None.

\section{References}

1. Akao M, Chun YH, Wada H, Esato M, Hashimoto T, Abe M, et al. Current status of clinical background of patients with atrial fibrillation in a community-based survey: The Fushimi AF Registry. J Cardiol 2013; 61: 260-266.

2. Iguchi Y, Kimura K, Aoki J, Kobayashi K, Terasawa Y, Sakai $\mathrm{K}$, et al. Prevalence of atrial fibrillation in community-dwelling Japanese aged 40 years or older in Japan: Analysis of 41,436 non-employee residents in Kurashiki-city. Circ J 2008; 72: $909-$ 913.

3. Kimura K, Kazui S, Minematsu K, Yamaguchi T; Japan Multicenter Stroke Investigator's Collaboration. Analysis of 16,922 patients with acute ischemic stroke and transient ischemic attack in Japan: A hospital-based prospective registration study. Cerebrovasc Dis 2004; 18: 47-56.

4. McGrath ER, Kapral MK, Fang J, Eikelboom JW, Conghaile A, Canavan M, et al. Association of atrial fibrillation with mortality and disability after ischemic stroke. Neurology 2013; 81: $825-832$.

5. Ruff CT, Giugliano RP, Braunwald E, Hoffman EB, Deenadayalu $\mathrm{N}$, Ezekowitz MD, et al. Comparison of the efficacy and safety of new oral anticoagulants with warfarin in patients with atrial fibrillation: A meta-analysis of randomised trials. Lancet 2014; 383: $955-962$.

6. Goyal M, Menon BK, van Zwam WH, Dippel DW, Mitchell PJ, Demchuk AM, et al. Endovascular thrombectomy after largevessel ischaemic stroke: A meta-analysis of individual patient data from five randomised trials. Lancet 2016; 387: 1723-1731.

7. Yasaka M, Minematsu K, Yamaguchi T. Optimal intensity of international normalized ratio in warfarin therapy for secondary prevention of stroke in patients with non-valvular atrial fibrillation. Intern Med 2001; 40: 1183-1188.

8. Shinohara Y. For readers (stroke specialists and general practitioners) of the Japanese guidelines for the management of stroke. Preface. J Stroke Cerebrovasc Dis 2011; 20(4 Suppl): S1-S6.

9. Inoue $\mathrm{H}$, Okumura $\mathrm{K}$, Atarashi $\mathrm{H}$, Yamashita $\mathrm{T}$, Origasa $\mathrm{H}$, Kumagai N, et al. Target international normalized ratio values for preventing thromboembolic and hemorrhagic events in Japanese patients with non-valvular atrial fibrillation: Results of the J-RHYTHM Registry. Circ J 2013; 77: 2264-2270.

10. Hacke W, Kaste M, Fieschi C, von Kummer R, Davalos A, Meier D, et al. Randomised double-blind placebo-controlled trial of thrombolytic therapy with intravenous alteplase in acute ischaemic stroke (ECASS II). Second European-Australasian Acute Stroke Study Investigators. Lancet 1998; 352: 1245-1251.

11. Nakamura A, Ago T, Kamouchi M, Hata J, Matsuo R, Kuroda $\mathrm{J}$, et al. Intensity of anticoagulation and clinical outcomes in acute cardioembolic stroke: The Fukuoka Stroke Registry. Stroke 2013; 44: 3239-3242.

12. Okumura Y, Yokoyama K, Matsumoto N, Tachibana E, Kuronuma K, Oiwa K, et al. Current use of direct oral anticoagulants for atrial fibrillation in Japan: Findings from the SAKURA AF Registry. J Arrhythm 2017; 33: 289-296.

13. Atarashi $\mathrm{H}$, Inoue $\mathrm{H}$, Okumura $\mathrm{K}$, Yamashita $\mathrm{T}$, Kumagai $\mathrm{N}$, Origasa $\mathrm{H}$, et al. Present status of anticoagulation treatment in Japanese patients with atrial fibrillation. Circ J 2011; 75: $1328-$ 1333.

14. Chishaki A, Chishaki H. To know the exact prevalence and prognosis of atrial fibrillation from a clinical survey - comments on the "The Fushimi AF Registry". J Cardiol 2013; 61: 304-306.

15. Hylek EM, Go AS, Chang Y, Jensvold NG, Henault LE, Selby $\mathrm{JV}$, et al. Effect of intensity of oral anticoagulation on stroke 
severity and mortality in atrial fibrillation. $N$ Engl J Med 2003; 349: $1019-1026$.

16. Ay H, Arsava EM, Gungor L, Greer D, Singhal AB, Furie KL, et al. Admission international normalized ratio and acute infarct volume in ischemic stroke. Ann Neurol 2008; 64: 499-506.

17. Stollberger C, Finsterer J. Presentation, therapy and outcome of patients with ischemic stroke under new oral anticoagulants. Neurol Neurochir Pol 2014; 48: 136-140.

18. Yoshimura S, Koga M, Sato S, Todo K, Yamagami H, Kumamoto $\mathrm{M}$, et al. Two-year outcomes of anticoagulation for acute ischemic stroke with nonvalvular atrial fibrillation: SAMURAI-NVAF Study. Circ J 2018; 82: 1935-1942.

19. Hirano T, Kaneko H, Mishina S, Wang F, Morita S. Suboptimal anticoagulant management in Japanese patients with nonvalvular atrial fibrillation receiving warfarin for stroke prevention. $J$ Stroke Cerebrovasc Dis 2017; 26: 2102-2110.

20. Nakamura A, Kuroda J, Ago T, Hata J, Matsuo R, Arakawa S, et al. Causes of ischemic stroke in patients with non-valvular atrial fibrillation. Cerebrovasc Dis 2016; 42: 196-204.

21. Shiga T, Naganuma M, Nagao T, Maruyama K, Suzuki A, Murasaki K, et al. Persistence of non-vitamin K antagonist oral anticoagulant use in Japanese patients with atrial fibrillation: A single-center observational study. J Arrhythm 2015; 31: 339-344.

22. Takagi T, Yoshimura S, Uchida K, Shirakawa M, Yamada K, Tatebayashi K. The current status of endovascular thrombectomy for acute ischemic stroke in Japan: Results of a nationwide questionnaire survey in 2016. J Neuroendovasc Ther 2017; 11: $504-511$.

\section{Supplementary Files}

Supplementary File 1

Table S1. Direct oral anticoagulant dose reduction criteria in Japan

Table S2. Clinical background characteristics of patients according to prior oral anticoagulant status

Table S3. Associations between baseline characteristics and admission stroke severity

Please find supplementary file(s);

http://dx.doi.org/10.1253/circj.CJ-18-0561 